\title{
UMA BIOGRAFIA MUSEALIZADA: A COLEÇÃO DE HUGO SIMÕES LAGRANHA NO MUSEU MUNICIPAL DE CANOAS (RS)
}

\section{- JULIA MACIEL JAEGER}

http://orcid.org/0000-0002-9620-2453

Universidade Federal do Rio Grande do Sul

\section{ZITA ROSANE POSSAMAI}

http://orcid.org/0000-0003-4014-5389

Universidade Federal do Rio Grande do Sul

RESUMO O presente artigo tem por objetivo aproximar duas práticas culturais de salvaguarda de memória: as escritas biográficas e as coleções museológicas. Ambas podem atuar como consagradoras de uma memória individualizante dos grandes exemplos ou como vetores de reflexões acerca das memórias coletivas. A partir de um estudo de caso oriundo da cidade de Canoas (RS), analisou-se a biografia autorizada do ex-prefeito Hugo Simões Lagranha, sua coleção em exposição no Museu Municipal de Canoas, os livros tombos do Museu e jornais locais. Considerou-se as coleções como atos biográficos e as exposições enquanto narrativas construídas por meio de objetos. Foi possivel compreender como a cidade de Canoas trata as memórias locais ao se distanciar da história da cidade e suas diversas nuances para representar a trajetória de um homem só.

Palavras-chave: Biografia. Coleção biográfica. Museu Municipal. Canoas.

\section{ABSTRACT A BIOGRAPHY IN THE MUSEUM: THE COLLECTION OF HUGO SIMÕES LAGRANHA IN THE MUSEU MUNICIPAL DE CANOAS/RS}

This article analyzes two cultural practices that aim to preserve the memories: the biographies and the museum's collections. Both can value individual memories or can serve to think about collective memories. This research recognizes collections as biography acts and the museum's exhibition as a discourse with the objects. The official biography of former mayor Hugo Simões Lagranha, his col- 
lection in exhibition in the Museum of Canoas and other documents were examined. From the empirical data it was possible to demonstrate that the museum values the representation of a single man in detriment of the representation of the city.

Keywords: Biography. Biographical collection. Municipal Museum. Canoas.

\section{RESUMO UNA BIOGRAFÍA MUSEALIZADA: LA COLEÇCIÓN DE HUGO SIMÕES LAGRANHA EN EL MUSEO MUNICIPAL DE CANOAS/RS}

Este artículo tiene como objetivo aproximar dos prácticas culturales de salvaguardia de la memoria: las escritas biográficas y las colecciones museológicas. Ambas pueden actuar como consagradoras de la memoria individualizadora de los grandes ejemplos o como vectores de reflexiones sobre las memorias colectivas. A partir de un estudio de caso oriundo de la ciudad de Canoas/RS y en base a las premisas de que las colecciones se constituyen en actos biográficos y las exposiciones como narrativas construidas por medio de objetos, se analizó la biografía autorizada del ex-alcalde Hugo Simões Lagranha, su colección en exposición en el Museo Municipal de Canoas, los libros catalogados del Museo y periódicos locales. A través de ese estudio, fue posible comprender como la ciudad de Canoas trata las memorias locales al distanciarse de la historia de la ciudad y sus diversos matices para representar la trayectoria de un hombre sólo. Palabras clave: Biografia. Colección biográfica. Museo Municipal. Canoas.

\section{Introdução}

A configuração de uma modernidade líquida, proposta por Bauman (2001), é o contexto escolhido por Hernández (2019) para situar os museus nos espaços e tempos contemporâneos. A comunicação globalizada, o ritmo acelerado da vida urbana, as rápidas mudanças e avanços tecnológicos são alguns dos aspectos que configuram uma experiência, cuja marca é a velocidade da passagem do tempo, chamada por Nora (1993) de "aceleração da História".

Nesse cenário de rápidas mudanças, no qual a liquidez configura todas as esferas da vida humana, emergem práticas que tentam reter o tempo, através da conservação de referências culturais pretéritas, a exemplo dos museus e dos patrimônios. De acordo com Huyssen:

Não é o sentido seguro das tradições que marcam a origem dos museus, mas a sua perda combinada com um desejo profundo pela (re-) construção. Uma sociedade tradicional sem um conceito teleológico secular não precisa de um museu, mas a modernidade é impensável sem um projeto museico. (HUYSSEN, 1994, p. 36)

Assim, a modernidade deu origem a essas instituições cujos propósitos também se trans- 
formaram ao longo de sua existência secular, a ponto de ser observada uma temporalidade específica dos museus. Eles nasceram vinculados a finalidades simbólicas, pedagógicas, científicas e nacionais e se metamorfosearam em uma variedade de formatos, desde aqueles vinculados à diversidade das culturas locais até aqueles inseridos numa lógica da sociedade de consumo de massa. Seja qual for a configuração adotada, os museus foram investidos como espaços e práticas mediadores entre a humanidade e o seu passado. Embora o museu tenha atualmente um programa muito mais amplo que conservar, pesquisar e expor os vestígios culturais e naturais, continua a ser o lugar por excelência da memória, ou das memórias escolhidas para serem perpetuadas por dadas coletividades. Sua presença na modernidade líquida não apenas corrobora um tempo calcado no presentismo (HARTOG, 2014), assim como deixa à mostra nossa ligação com um passado que não quer passar, mas que é ressignificado num horizonte de expectativas (KOSELLECK, 2006).

Desse modo, a criação de museus e a multiplicação dos patrimônios passam estar na ordem do dia para alguns países, como a França envolvida por uma onda comemorativa no final dos anos 1980 (CHOAY, 2001; HARTOG, 1996), situação que não pode ser generalizada para outros contextos nacionais e muito menos para o Brasil, onde as políticas culturais e patrimoniais não apresentam a mesma estabilidade que os países europeus.

Entretanto, guardadas as particularidades de cada país, no Brasil, é possivel observar práticas de perpetuação das memórias através dos museus, especialmente quando se trata de instituições criadas em pequenas localidades. No caso aqui estudado, o desejo de memória de uma cidade imbrica-se com a vontade de eternização da memória individual por meio do museu. Para realizar a análise, considera- mos o desafio de cruzar duas práticas culturais distintas, o museu e a biografia, por ambos apresentarem um campo fértil para a análise dos processos de construção e perpetuação de memórias de indivíduos na sociedade.

Vale lembrar que, no Brasil, a presença do personagem nos museus remonta há várias décadas. Os grandes fatos e grandes heróis nacionais ou regionais foram a marca de coleções e exposições das instituições museológicas às quais foi dado o papel de elaborar narrativas sobre o passado, tais como o Museu Paulista (BREFE, 2005), o Museu Histórico Nacional (ABREU; 1996; MAGALHÃES, 2003; SANTOS, 2006), o Museu Júlio de Castilhos (SILVA, 2018), o Museu Paranaense (CARNEIRO, 2013; RODRIGUES, 2018). Esse aspecto esteve intimamente ligado à presença, nesses museus, de homens vinculados aos Institutos Históricos e Geográficos, que, entre final do século XIX e primeira metade do século $X X$, estavam comprometidos com a elaboração da história nacional e regional nos moldes dos pressupostos positivistas apropriados pela historiografia brasileira. Para esses pesquisadores, era relevante não apenas reunir os documentos escritos sobre a história de personagens e acontecimentos marcantes a eles relacionados, mas também criar imagens para compor o panteão dos heróis em narrativas visuais expográficas ou documentais, embora Augusto Comte não acreditasse nas forças individuais como motor da história (SCHMIDT, 2012). Desse modo, é possível observar que as práticas de construir memórias e musealizar biografias estão presentes na história dos museus brasileiros e se perpetua ao longo do tempo, com mais ou menos ênfase, de acordo com os contextos e tipologias museológicas.

No campo da História, a biografia foi renovada especialmente com os aportes da terceira geração da Escola dos Annales (SCHMIDT, 2012) e da historiografia marxista inglesa. Mui- 
to mais que estimular valores a serem seguidos como exemplos ou oficializar uma memória dos vencedores, a História hoje se utiliza das biografias para relacionar as normas sociais e as ações individuais, projetando os aspectos da macro-história no âmbito individual (SCHIMIDT, 2012). Entretanto, pode se afirmar sem incorrer em equívoco, que muitos museus não se apropriaram dessa renovação epistemológica da biografia ocorrida no campo da História, quando abordam a trajetória de um único sujeito. Além disso, furtam-se ao desafio de representarem a diversidade cultural das sociedades contemporâneas e de se constituírem em arenas de reflexão e debate para um público cada vez mais exigente. Em diversas instituições museológicas brasileiras, ainda se encontram práticas de outrora, nas quais a vontade de uma memória personalizada se sobressai às premissas atualizadas desses saberes. Um exemplo está localizado na cidade de Canoas, no Rio Grande do Sul, Brasil.

Neste artigo, partiremos da concepção Meneses $(1998,1994)$, que entende as coleções como atos autobiográficos e as exposições como forma de discurso construído por meio de objetos, a fim de analisar como foi musealizada a memória e a biografia do ex-prefeito Hugo Simões Lagranha. A pesquisa se constitui em um estudo de caso, para o qual foram analisados os seguintes documentos: a biografia Simplesmente Lagranha, escrita por Oliveira (2002), notícias de jornais locais, os livros tombos do acervo tridimensional do Museu e a exposição de longa duração do Museu, entendida aqui como um discurso biográfico.

\section{Hugo Simões Lagranha e a memória da cidade}

Antes de adentrar nas problemáticas sobre o museu da cidade de Canoas, consideramos importante contextualizar o meio urbano no qual ele está inserido. Canoas é uma cidade da região metropolitana de Porto Alegre, no Rio Grande do Sul, Sul do Brasil, e faz divisa com os municípios de Esteio, Porto Alegre, Cachoerinha e Nova Santa Rita. Sua origem remonta os anos de 1730, e a urbanização da cidade teve início em 1870, com a construção da linha férrea que uniu Porto Alegre à São Leopoldo, importante centro de produção hortifrutigranjeira de colonização imigrante. Canoas começou sua urbanização como uma cidade de veraneio e, atualmente, conta com 323.827 habitantes. Transformou-se em um polo industrial, e muitos dos avanços urbanos ocorreram nas gestões do ex-prefeito Hugo Simões Lagranha, que viria a dar nome ao Museu.

Hugo Simões Lagranha nasceu em 1918, em Alegrete, cidade localizada no oeste do Rio Grande do Sul. Formado em Administração, começou sua carreira política em Canoas, no Partido Social Democrático (PSD) em 1954, pelo qual foi vice-prefeito e prefeito da cidade. Nos anos da Ditadura Civil-Militar (1964-1988), com a extinção dos partidos políticos em virtude do Ato Institucional no 2 , de 27 de outubro de 1965, e a consequente instituição do bipartidarismo, ingressou na Aliança Renovadora Nacional (Arena), pela qual ocupou os cargos de prefeito e vereador de Canoas. Com a extinção do bipartidarismo, em novembro de 1979, filiou-se ao Partido Democrático Social (PDS), sucessor da Arena. Após esse período, o ex-prefeito transferiu-se para outros partidos entre 1983 e 2000, tendo sido filiado ao Partido Democrático Trabalhista (PDT), ao Partido Progressista Reformador (PPR) e ao Partido Trabalhista Brasileiro (PTB), no qual permaneceu até o final da sua vida política.

Lagranha foi prefeito de Canoas por cinco mandatos, além de ter exercido os cargos de vereador e deputado federal, nos quais também representava a cidade. Foi um político que construiu sua imagem acima dos partidos 
aos quais se associava. Como exemplo disso, em 1968, após a Arena perder a eleição para o Movimento Democrático Brasileiro (MDB), um dos vereadores da legenda colocara a culpa da derrota do partido no Diretório Municipal de Canoas, nos candidatos escolhidos e no próprio prefeito Lagranha, que "durante 5 anos foi quase personalizado e não deu apoio político a ninguém" (O TIMONEIRO, 1968 apud FUNDAÇÃO, 2009, p. 93).

Figura 1 - Hugo Simões Lagranha.

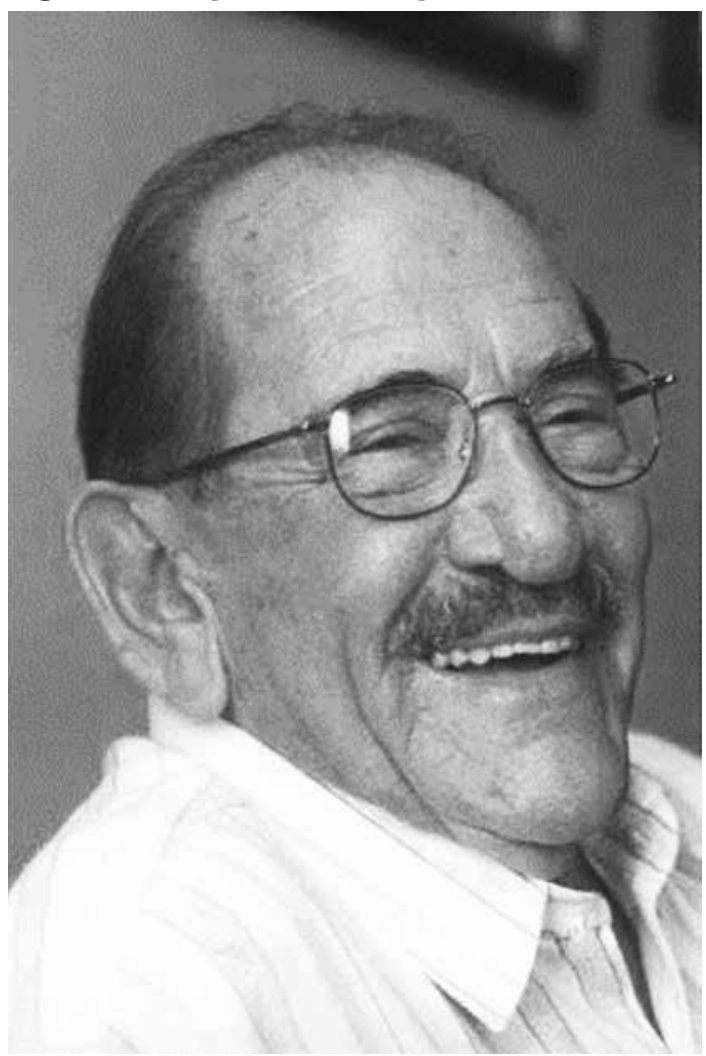

Fonte: 8 ANOS..., $2013 .^{1}$

Seu jeito de ser e posicionamentos firmes causaram alguns momentos de tensão, como quando os vereadores da Câmara de Canoas protestaram contra uma fala de Lagranha, na qual insinuara que eles não faziam nada durante o dia todo (O TIMONEIRO, 1970 apud FUNDAÇÃO, 2009). Ou como quando foi ameaçado de morte por telefone, em 1968 (OPINIÃO PÚ-

18 ANOS sem Lagranha. Voz Nativa Comunicações, Canoas, 15 de abril de 2013. Disponível em: http://www. grupovoznativacomunicacoes.com.br/2013/04/8-anos-sem-lagranha.html. Acesso em: 20 nov. 2019.
BLICA, 1968 apud FUNDAÇÃO, 2009). Apesar das desavenças políticas, os jornais locais apontam que suas gestões trouxeram melhorias significativas para os bairros da cidade, bem como desenvolvimento e modernização para todo o tecido urbano. Isso garantira ao prefeito inúmeros troféus e medalhas de mérito, oferecidos por diversos órgãos municipais e estaduais, associações de moradores, empresas locais e figuras representativas da cidade (ARQUIVO HISTÓRICO E MUSEU DE CANOAS, 2006).

Na posição de prefeito, antes da existência do Museu Municipal de Canoas, a Hugo Simões Lagranha eram confiados pelos moradores objetos de valor histórico para a cidade, tais como o sino tocado pela Princesa Isabel em sua visita à região de Morretes (atual Nova Santa Rita), oferecido, em 1969, à Lagranha pelo antigo capataz da região (ARQUIVO HISTÓRICO E MUSEU DE CANOAS, 1989) e o diário pessoal de Santos Ferreira, um dos primeiros moradores da cidade. Era, portanto, considerado por alguns canoenses como um guardião da memória do município.

Esse engajamento com a memória local esteve presente nas gestões de Lagranha. Em 1969, instituiu a Semana de Canoas com vistas à divulgação da história local e, em 1986, criou a Fundação Cultural, a fim de promover história, cultura e arte na cidade. Em 1990, em sua quinta e última gestão, Hugo Simões Lagranha criou o Museu Municipal de Canoas, por meio da Lei no 3.002. Observa-se nesse movimento uma vontade de memória dos citadinos acerca da história local e uma busca por salvaguardar um passado comum.

Com a missão de "[...] conservar, pesquisar e divulgar os testemunhos materiais produzidos pelos canoenses ao longo dos anos" (1a REGIÃO MUSEOLÓGICA DO RIO GRANDE DO SUL, 2012), começa a atuação do Museu Municipal de Canoas, coletando objetos relativos ao pas- 
sado da cidade e seus sujeitos. Nessa primeira fase do Museu, Hugo Simões Lagranha doou os objetos a ele confiados e também outros objetos que remetiam ao passado e a crenças locais (ARQUIVO HISTÓRICO E MUSEU DE CANOAS, 1989).

Entre os anos de 1990 e 2007, através dos jornais, observa-se uma atuação plural do Museu na cidade, com a promoção de exposições sobre as mais diversas temáticas, ações educativas, de pesquisa e de promoção cultural na cidade. Além de ir ao encontro de doadores em potencial, a instituição promovia campanhas para doação de acervos. Suas exposições abordavam diversos temas sobre a cidade e sobre temáticas pertinentes ao citadino e, muitas vezes, deixavam o espaço físico do $\mathrm{Mu}$ seu e eram montadas nas ruas, em shoppings e em centros comerciais, locais de maior circulação de pessoas e público potencial (A MEMÓRIA..., 1991; ARQUIVO..., 1994; ARQUIVO..., 2003; EXPOSIÇÃO..., 1998; LAMPERT, 1996; OLIVEIRA, 1998; SILVA, 1995).

Além dessas atividades, o Museu desenvolvia iniciativas de pesquisa sobre a memória da cidade, como o Projeto "Canoas: Para lembrar quem somos", desenvolvido junto à Universidade La Salle e o Projeto "Nossos Prefeitos", em parceria com a prefeitura. Essas investigações resultaram em publicações que compilaram informações e documentação antes dispersas acerca da história do município. Os servidores do museu ainda participavam dos Fóruns da área (CANOAS, 1989; CANOAS, 1990) e coordenaram a 1ạ Região Museológica do Estado do Rio Grande do Sul (MUSEOLOGIA, 1993).

No ano de 2002, foi lançada uma biografia do ex-prefeito Lagranha. Escrita pela professora e funcionária da Prefeitura de Canoas Miriam Kinczel de Oliveira (2002), o livro de 92 páginas, Simplesmente Lagranha: Homem, marido, pai, político e administrador teve a publicação autorizada pelo ex-prefeito. A autora se utilizou de matérias jornalísticas e de entrevista para compor a narrativa, entretanto, não explicita em sua narrativa a metodologia adotada na pesquisa. Ao contrário, não é possível identificar um problema que norteie a escrita (SCHMIDT, 2012), além da intenção de elaborar uma narrativa do personagem a partir dos seus múltiplos papéis sociais. Assim, a biografia narra a vida do personagem sem seguir os parâmetros acadêmicos da História, embora contenha elementos passiveis de análise por esse campo, tendo em vista que qualquer escrito pode ser transformado em documento do passado (LE GOFF, 2003).

Três anos depois, o biografado faleceu em decorrência de um câncer, aos 87 anos. Não foi possivel saber se quando da elaboração e publicação de sua biografia, o prefeito já estava sofrendo dessa doença. Entretanto, temos a hipótese de que ao antever sua morte, houve uma preocupação, sua ou de sua esposa Derna Maria Paim, em legar à posteridade uma biografia autorizada. Desse modo, a confirmar-se essa possibilidade, pode-se pensar em uma vontade de memória de Lagranha, efetivada por ele mesmo ainda em vida ou por sua esposa. ${ }^{2}$

Dois anos após sua morte, em 2007, a viúva do ex-prefeito satisfez a vontade do seu esposo e realizou a doação de todo o escritório pessoal de Lagranha para o Museu Municipal. Nesse sentido, ao que tudo indica, o desejo de perpetuar-se, seja em biografia, seja no Museu, era do próprio prefeito e havia sido expresso a sua esposa ainda em vida. Por meio da biografia e da coleção doada ao Museu, a memória de Lagranha pode ser construída e pereniza-

2 Essas práticas de imortalização de determinados indivíduos são comuns nos museus, através da doação de seus objetos ou da criação de imagens post-mortem. A esse respeito, ver Regina Abreu (1996), sobre a doação da coleção Miguel Calmon ao Museu Histórico Nacional e Ana Celina da Silva (2018) sobre a perpetuação da memória de Júlio de Castilhos no Museu do Estado do Rio Grande do Sul. 
da. Contudo, esse desejo de imortalização e a doação a ele relacionada modificaram indelevelmente o Museu Municipal de Canoas.

\section{Biografia e museu: memória da cidade ou memória biográfica?}

A escrita biográfica e as coleções autobiográficas surgem em decorrência de uma vontade de memória, seja essa uma vontade individual ou social. Essas duas práticas de memória se assemelham nesse ponto, e em alguns outros que iremos discorrer abaixo.

A biografia é uma escrita da história controversa nesta área do conhecimento. Por muito tempo, foi considerada um gênero literário, escrito por amadores e "pouco capaz de possibilitar uma compreensão efetiva do passado" (SCHMIDT, 2012, p. 187). No século XIX, essa escrita teve um papel muito importante na criação dos ideais de nação, ao imortalizar os grandes "heróis" que auxiliaram na construção do país, consolidando um patrimônio feito de exemplos a serem seguidos. Teresa Maria Malatian exemplifica essa concepção ao abordar a forma com que Thomas Carlyle ${ }^{3}$ usava a biografia de personalidades heroicas para interpretar a história no início do século XIX:

O herói individual, sujeito de exaltação, foi por Carlyle encarregado de exprimir sua época e, assim, a História se tornou o campo de afrontamento de personalidades heroicas, cada uma com sua função profética enquanto encarnação das forças do Espírito, entendidas como religião, 'o fator principal na vida do homem'. Entre eles, o herói demiurgo seria capaz de dar sentido à história e forçar o destino. Em sua obra de referência e exaltação do idealismo, Os heróis e o culto dos heróis, atribuiu aos indivíduos excepcionais um papel na História da humanidade, confundindo-a com a dos 'grandes homens que trabalharam a terra: eles foram os condu-

3 Thomas Carlyle foi um escritor, historiador, ensaísta e professor escocês. Nasceu na Escócia em 1795 e faleceu em 1881em Londres. tores, os modeladores, os padrões e, num largo sentido, os criadores de tudo o que a massa geral dos homens procurou fazer ou atingir' (CARLYLE, [s.d], p. 9, apud MALATIAN, 2008, p. 17).

Essa concepção foi retomada pela corrente positivista, na qual "[...] a biografia assimilou-se à exaltação das glórias nacionais, no cenário de uma história que embelezava o acontecimento, o fato" (PRIORE, 2009, p. 8). Nas décadas de 1980 e 1990, acompanhou-se o florescimento da História Oral, bem como das autobiografias e documentos pessoais como fonte de pesquisa histórica (PEREIRA, 2000). Nesse momento, emergia o entendimento de que as trajetórias pessoais faziam parte de um contexto histórico, devendo ser levadas em conta para analisar as relações em sociedade em determinado período como um todo. Desse modo, a biografia passou a levar em consideração o meio social e as relações e representações em torno do indivíduo (OLIVEIRA; OLIVEIRA, 2015).

É importante frisar o papel do historiador/ biógrafo no processo de construção da narrativa da trajetória de vida do biografado. Nesse sentido, Márcia Ramos de Oliveira (2016, p.112) atenta para esse fato, indicando que "[...] à medida em que constrói a biografia, o historiador torna-se parte do processo, legitimando/ autorizando representações, desvelando ou criando fatos que dão contorno aos personagens por sua atuação, diante de base documental". A escrita da História, não pode, como nos alerta Certeau (2011), ser entendida como uma produção desprovida de seletividades, intencionalidades, de escolhas.

Biografar é, portanto, um ato de seleção e organização de fatos e criação de uma narrativa. Contudo, neste trabalho, não se pretende assumir o sentido estrito da biografia, conforme enunciado por esses autores, mas considerar que as instituições voltadas à memória têm papel importante na valorização de percursos 
individuais, a exemplo da preservação dos arquivos pessoais e das coleções autobiográficas (MENESES, 1998) dos museus. Nas palavras de Abreu (1996, p. 100):

[...] para o culto do eu, a memória é vital. É preciso salvar do esquecimento, do esfumaçamento provocado pela morte, individualidades tão ricamente elaboradas. 0 sujeito busca então a eternização na memória dos outros sujeitos, guardando e arquivando testemunhos evocativos de suas obras e realizações. Desse modo, acredita-se poder superar, ao menos em parte, a tragédia da mortalidade humana.

Assim, nessas instituições, uma seleção de documentos, imagens e objetos alçados à condição de semióforos (POMIAN 1984) por representarem certos indivíduos, visam à preservação e à comunicação de suas trajetórias de vida. Cícero Antônio F. de Almeida (2011, p.185) aponta que "[...] nenhuma homenagem póstuma poderia ser melhor do que ter a coleção guardada em um museu, pois que permitirá ao colecionador ser também autor de uma 'obra', que deixa legado à posteridade". Ao ser incorporada a um museu, a coleção é legitimada como significativa para a sociedade. Quando falamos de uma coleção que pertencia ao doador de forma a representá-lo, a obra preservada pela instituição museológica é, na verdade, a sua própria vida. Conforme Pomian (1984), a coleção enseja o invisível, nesse caso, o indivíduo já desaparecido, através da visibilidade dos seus artefatos guardados ou expostos no museu. Os objetos que compõem uma coleção pertenceram a alguém e em alguns casos acabam por representar a vida dessa pessoa. Nesse sentido, os objetos podem nos "dizer" muito sobre seus possuidores, pois são evocativos da memória de seus donos, do período em que eram utilizados, dos acontecimentos que presenciaram (DOHMMAN, 2013). Pode-se dizer que constituem uma biografia material.
Por outro lado, a musealização, processo de incorporação de uma coleção a um museu, envolve a transformação do objeto em documento que informa sobre a sociedade (MENESES, 1994) e em monumento (LE GOFF, 2003) por suas características de unicidade e autenticidade. Inserido no museu, o objeto passa a ser objeto de curadoria ou da cadeia operatória que caracteriza a musealização e abarca as ações de aquisição, de pesquisa, de conservação, de documentação e de extroversão (BRUNO, 2006; CURY, 1999). Entre as ações que envolvem a extroversão, situa-se a exposição, caracterizada por uma narrativa espacial, material e visual, a partir da qual se estabelece a comunicação entre os objetos expostos e os públicos visitantes.

Biografar é um ato de seleção e organização de fatos e composição de uma narrativa acerca de uma pessoa com o intento de perenizar e dar a ver um itinerário de vida. Nesse sentido, pode ser aproximada ao processo de musealização. Podemos afirmar, assim, que a coleção musealizada e exposta no museu apresenta aproximações e distanciamentos a uma biografia escrita sobre o sujeito. A biografia é sempre uma narrativa escrita sob formato de livro. É escrita por meio da lógica de seu produtor, o autor, ao qual é possibilitado o detalhamento das descrições psicológicas, das intrigas, dos enredos, como é do caráter do texto. Embora o texto biográfico não prescinda de seu leitor para a construção de significados e interpretações, pois cada pessoa lê a seu modo, ao autor é reservada a liberdade para criar o seu enredo nos moldes em que deseja (CHARTIER, 1992). A coleção, ao contrário, é a reunião de artefatos, imagens e documentos em estado bruto e necessita da operação museográfica para adquirir sentido. Os objetos da coleção, desse modo, somente após serem pesquisados e dispostos numa narrativa expográfica adquirem significado, proposto ao visi- 
tante. Esse observador, por sua vez, também é livre para criar outros sentidos de acordo com seu olhar.

Desse modo, ao ler uma biografia, o leitor conhece a vida de determinado indivíduo, suas marcas de personalidade, seus desejos recônditos, suas relações pessoais e profissionais, seus afetos e desafetos, seus valores, num mergulho capaz de tornar o biografado intimo. A coleção, por sua vez, pode ensejar todos esses aspectos, mas dependem dos objetos que a compõem para tal. $\mathrm{Na}$ exposição, aproxima-se, desse modo, a uma narrativa por saltos, na qual o fio condutor é dado pelos objetos evocadores da vida de determinado personagem. Atua por brechas, lacunas, cheios e vazios propostos ao visitante, responsável por montar um mosaico da vida apresentada, uma biografia material.

A biografia Lagranha (2007), Simplesmente Lagranha, foi constituída através de informações fornecidas pelo próprio biografado e obtidas em revistas e jornais da cidade e no Museu de Canoas (KINCZEL, 2002). Em nota de abertura, a autora afirma que "[...] espera contribuir de alguma forma para enriquecer a história de Canoas, oferecendo aos leitores a oportunidade de um contato maior com o cotidiano de um filho ilustre, natural de Alegrete, mas que adotou Canoas como "pátria mãe" (OLIVEIRA, 2002, p. 9). Nessa frase, observamos duas características da biografia no século XIX, adotadas nessa obra. Por um lado, aborda 0 brasileiro ilustre construtor da nação, nesse caso, da cidade. Por outro lado, apresenta sua história de vida sem conexão com o contexto histórico e cultural vigente.

Ao longo da publicação, Kinczel (2002) usa expressões como: "nada impediu que se constituísse em uma figura respeitada"; "desde pequeno [...]"; "antes precisava cumprir uma missão"; "sob a dinâmica de grandes homens". Essa maneira de biografar é refutada por Pier- re Bourdieu (2006), pois o historiador/biógrafo que coloca o indivíduo como destinado para ocupar determinada posição desconsidera os inúmeros fatores, incertezas, relações e contradições que competem a uma vida. 0 autor aborda a noção de "trajetória" como "[...] série de posições sucessivamente ocupadas por um mesmo agente (ou um mesmo grupo) num espaço que é ele próprio um devir, estando sujeito a incessantes transformações" (1996, p.189, grifo do autor).

De fato, por suas características, essa biografia não se insere na compreensão que a História tem atualmente acerca da escrita biográfica, mas consiste em um objeto para entendimento da construção da figura de Hugo Simões Lagranha na cidade de Canoas. A memória acerca dessa figura começou a ser elaborada enquanto Lagranha ainda era vivo e teve narrativa e recortes influenciados por ele, como é possível identificar no capítulo final da biografia: "Lagranha tem uma história de vida voltada para a política e, certamente, valiosa e riquíssima, mas preferiu ater-se a fatos que realmente fossem relevantes e do interesse de pessoas que gostariam de conhecer um pouco da sua trajetória [...]" (OLIVEIRA, 2002, p. 91, grifo das autoras).

Essa influência do ex-prefeito é também observada no processo de doação de sua coleção para o Museu Municipal de Canoas, visto que desde a criação da instituição o ex-prefeito manifestava vontade de ter seus pertences salvaguardados para que as futuras gerações pudessem ter mais aportes materiais de memória da cidade. E foi para honrar essa vontade de memória do ex-prefeito que sua viúva doou todos os objetos do escritório pessoal do marido para o Museu em 2007.

Possamai (2010, p. 65) afirma que os objetos de museu se distinguem de duas formas: a partir do processo de musealização - procedimentos de classificação, inventário, etiquetagem - e “[...] outra quando ele é o resultado de uma es- 
colha, expressa na sua admissão no interior de uma coleção". Não por acaso, os objetos de Lagranha foram incorporados ao acervo do Museu de Canoas, movimento que denota motivações individuais (do ex-prefeito, de sua viúva, do funcionário que recebeu a doação) ou sociais (do Museu, instituição destinada à salvaguarda da cultura material canoense). Assim, a vontade de preservação da memória de Lagranha, por sua parte - que quando em vida manifestou o desejo de ter seus objetos expostos e sendo úteis à comunidade canoense -, por parte de sua família - que efetuou a doação - e por parte do Museu - que incorporou a coleção no seu acervo - efetivaram essa transição de objetos comuns para objetos museológicos.

Foi nesse mesmo movimento que a instituição passou a homenagear o ex-prefeito Lagranha, com a aprovação da Lei Ordinária no 5.182 de 2007, aprovada em unanimidade na Câmara de Vereadores de Canoas (LAGRANHA, 2007). A partir de então, o Museu Municipal de Canoas recebeu um patrono e foi denominado Museu Hugo Simões Lagranha, cuja coleção passou a ser exposta em uma das salas da instituição.

A coleção Hugo Simões Lagranha é composta pelos móveis, os troféus de honra ao mérito, os livros, algumas borrachas, lápis, kits de primeiros socorros, enfim, tudo que se encontrava no escritório. Ao todo, a coleção possui 358 objetos. Até o momento da doação, o museu possuía 787 objetos tridimensionais listados em seu livro de tombo. A coleção de Lagranha, na época, correspondia a aproximadamente $45 \%$ do acervo total do Museu Municipal de Canoas (ARQUIVO HISTÓRICO E MUSEU DE CANOAS, 2006).

A exposição de longa duração referente ao ex-prefeito passou por algumas modificações ao longo dos anos, principalmente após a mudança de sede para a Casa dos Rosa em 2016.

4 Primeira edificação da cidade de Canoas. Restaurada em 2016 para abrigar o Museu Hugo Simões Lagranha.
Nessa nova sede, após mudança de gestão ${ }^{5}$ em 2017, o museu passou a ter três salas expositivas, distribuídas em $80 \mathrm{~m}^{2}$. Uma das salas abriga a exposição permanente do museu, dedicada exclusivamente ao acervo do ex-prefeito, denominada aqui de sala "Gabinete de Lagranha", pois visa recompor o escritório pessoal do ex-prefeito, com os mobiliários, alguns troféus, livros e alguns itens decorativos, como se ainda tivesse sua função original. Além dessa, possui duas salas de exposições temporárias, as quais, em um período de menos de três anos abrigaram duas exposições que também fizeram referência ao ex-prefeito (uma exposição sobre os patronos das instituições de memória da cidade e uma exposição sobre o centenário de nascimento do ex-prefeito). 0 foco desta pesquisa será na sala Gabinete de Lagranha (Figura 2).

Figura 2- Exposição do acervo de Lagranha.

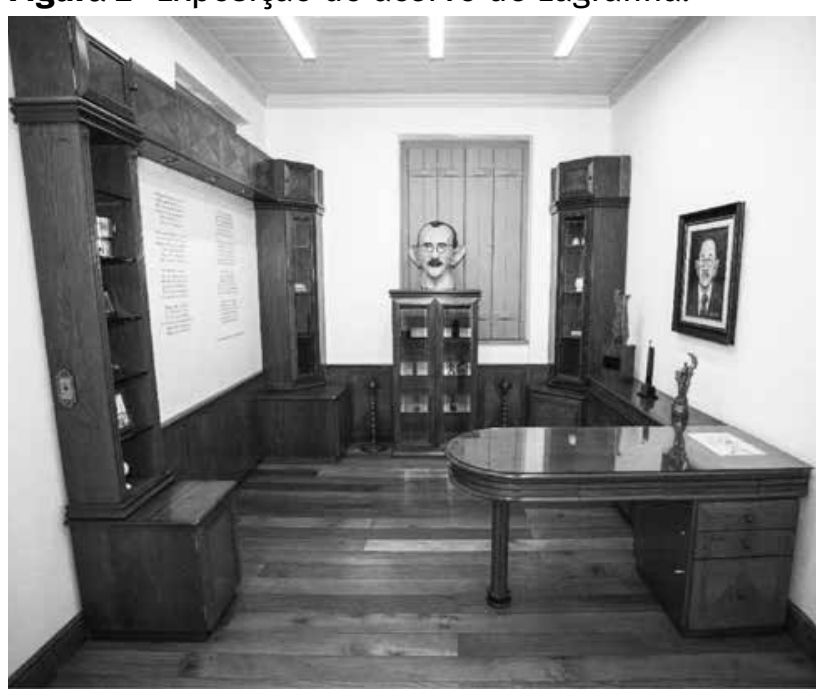

Fonte: Vinicius Thormann, 2019.

Exposição é um discurso sem texto, e de acordo com Meneses:

Aquilo que é a monografia, no domínio da palavra escrita, seria a exposição ('monoplastia'?) no domínio dos objetos - o que, todavia, não pode equivaler a transformara exposição

5 Para mais informações sobre o processo de mudança de sede do Museu do município para a Casa dos Rosa e do processo de concepção da exposição, ver Jaeger (2017). 
num trabalho acadêmico. Seja como for, a exposição, na linha aqui desenvolvida, pressupõe a articulação de enunciados sobre certos problemas humanos, desenvolvidos com o suporte das coisas materiais. (MENESES, 1994, p. 37)

É na exposição que entramos em contato com o discurso que a instituição promove e transmite aos seus visitantes, tal qual num texto biográfico. Enquanto a biografia estrutura sua narrativa por meio de palavras, a exposição utiliza objetos musealizados. Ao retomar o pressuposto de Ulpiano T. Bezerra de Meneses (1998) de que coleções são atos autobiográfi- cos, iremos analisar a construção do personagem através da exposição de longa duração da Casa dos Rosa, referente ao acervo de Hugo Simões Lagranha, patrono da instituição, na sua composição do primeiro semestre de 2019.

Na sala de exposição dedicada a reproduzir o escritório pessoal de Lagranha, encontram-se três imagens reproduzidas do ex-prefeito: uma pintura de Wagner Costa retratando a face do ex-prefeito; um busto de autoria não identificada; e uma caricatura (também não foi identificada a rubrica do artista), conforme Figura 3.

Figura 3 - Montagem das representações imagéticas do ex-prefeito.
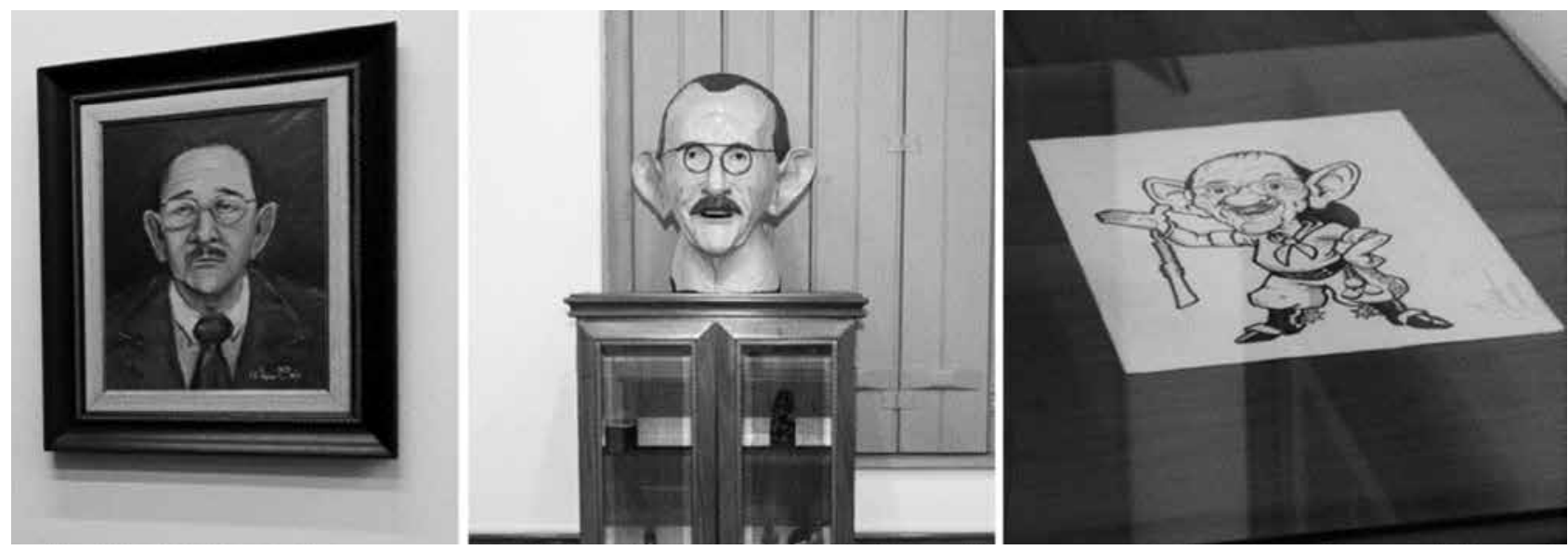

Fonte: acervo das autoras, 2019.

Esses objetos evidenciam um discurso imagético de apologia à figura do ex-prefeito.

Entendendo a exposição como uma forma de comunicação, um discurso criado a partir dos objetos e dos suportes expositivos, as imagens repetitivas do ex-prefeito corroboram na construção dessa figura no imaginário dos visitantes.

O único texto presente nessa sala da exposição é um poema escrito por João Palma da Silva - escritor e historiador da cidade de Canoas no qual ele agradece a Hugo Simões Lagranha o auxílio e reconhecimento prestado ao Galpão Sede do Centro de Tradições Gaúchas Rancho Criolo em 1968, reproduzido abaixo:
O Hugo Simões Lagranha. Velho Guasca alegretense, Tem algo que lhe pertence, E ninguém pode apagar; Ele sabe governar, Esta terra canoense.

Tem certas baldas e manhas Do velho Antônio Chimango, Mas parece mais um frango, Cria de galo de rinha, Sugerindo pela linha, Um dançarino de tango. Quando aqui apareceu, Diziam as línguas à toa Que vem fazer em Canoas Esse tipo de empertigado? 
Vem lá da terra do gado

E as aparências são boas...

Houve, depois, eleição

E o Lagranha foi eleito

Para ser vice-prefeito.

Mas, depois, com muitas lábias,

Parecendo das Arábias,

Elegeu-se para Prefeito.

Inda é cedo para julgar

Quem ainda nos governa...

Terá entrado em baderna

E bem pode ainda entrar;

Assim não vou enfiar

Na laçada minha perna....

Mas do homem-cidadão

-Sem política e artimanha-

Posso dizer que o Lagranha

É bom amigo e sustento

Que tem cultura e talento

E sobe ainda a montanha.

E ninguém lhe negará

As obras realizadas,

Que já são favas contadas

Em seu acervo de glórias,

o que fez já está na História

Com letras de ouro gravadas.

E aqui, meu Prefeito,

Dos gaúchos, a gratidão,

Por dar 'Rancho' uma mão,

Construindo sede nova

Em lugar da que ia à cova

Sepultando a Tradição.

(SILVA, 1968, grifo das autoras)

O texto distribui elogios a Hugo Simões Lagranha, seja para aspectos da sua vida como gestor público, seja para seu caráter na vida privada. A parte destacada em itálico evidencia a exaltação à figura do ex-prefeito. As palavras usadas, "obras realizadas" e "acervo de glórias" são características do culto aos heróis, e assegura e justifica um lugar na História da cidade por conta disso. Lagranha já teria seu local na História por ser exemplo de gestão e caráter à população canoense.
Do outro lado da sala (Figura 4), encontramse livros, uma máquina de escrever, alguns dos troféus que compõem a coleção e fotografias emolduradas e dispostas na estante. Reunidos, esses artefatos compõem uma representação simbólica que remete a um homem intelectual, sendo a máquina de escrever o seu “instrumento de trabalho". A mesa, cadeira e máquina de escrever, na realidade, não fazem parte da doação de Derna Maria Paim. A mesa era a utilizada na sala dos prefeitos antigamente, e foi doada pela prefeitura, mas, nesse contexto, evoca o oficio que Lagranha exerceu durante muitos anos de sua vida.

Figura 4 - Exposição do acervo de Lagranha.

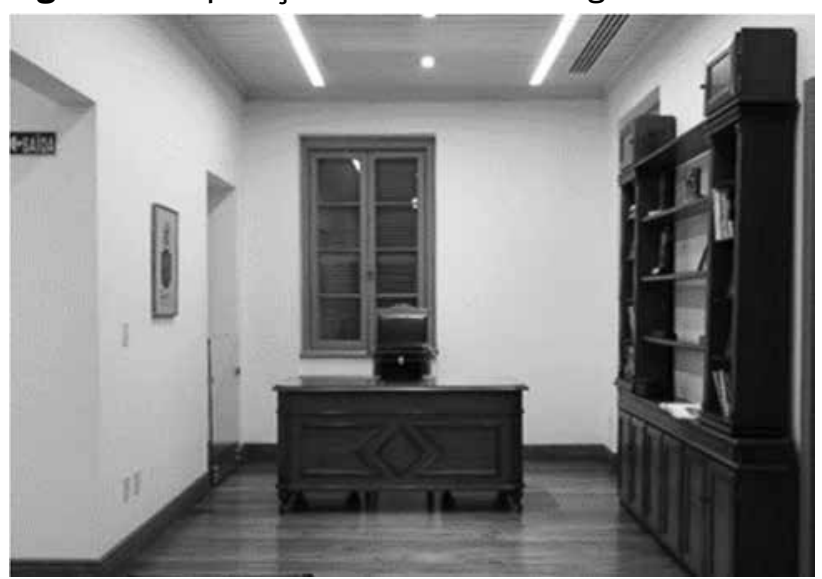

Fonte: acervo das autoras, 2019.

Um objeto interessante nessa parte da exposição é o brasão da família Lagraña (Figura 5), que deu origem à família do ex-prefeito. Os brasões, originados na Europa Medieval, se constituíram primeiramente em uma homenagem concedida a grandes cavaleiros por seus atos de bravura e, posteriormente, passaram a ser um item de status conferido às famílias nobres. Funcionava como um identificador de classe social, e era transmitido para as gerações futuras (CAMPACCI, 2012). Apesar da ausência de um texto explicativo sobre o brasão na exposição, a existência desse objeto indica a distinção do ex-prefeito, não apenas por seus atos individuais, mas também pela destacada família. 


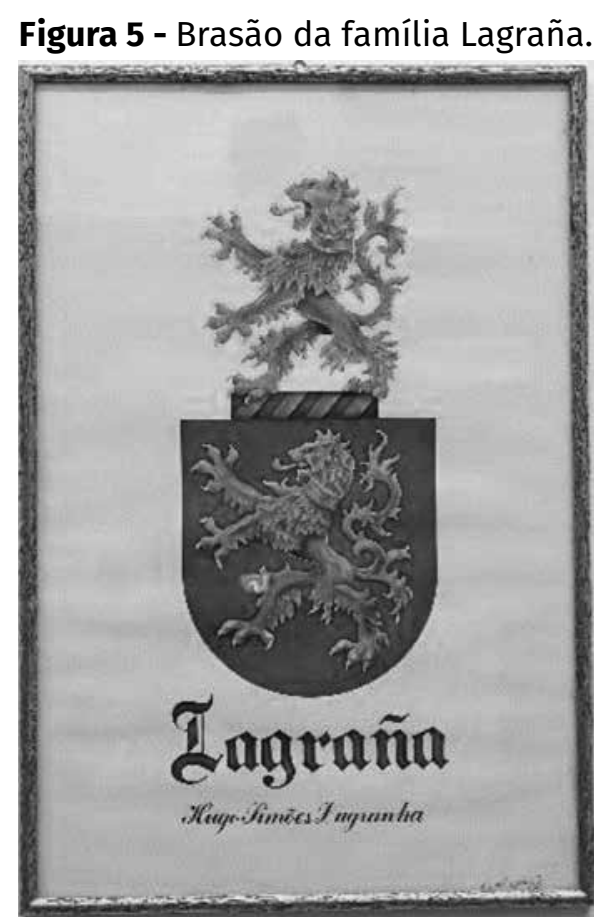

Fonte: acervo das autoras, 2019.

A ausência de textos expositivos e de legendas explicativas acerca dos objetos e sua relação com o ex-prefeito inserem esses artefatos numa lógica de fetichização (MENESES, 1994). Sem o auxílio de um mediador preparado e conhecedor da coleção, do ex-prefeito e da história local, não ficam evidentes as nuances que esses objetos possuem, nem qual o período Lagranha atuou como prefeito ou mesmo a relação que há com a história da cidade de Canoas. Considerando que uma exposição tem que ser suficiente para o visitante compreender o discurso museal sem o auxílio de mediadores externos (BLANCO, 2009, p. 36), o que essa exposição comunica é que Lagranha foi importante para a cidade. Mas não dá indícios de como se deu a trajetória desse homem ou sua relação com a história local. Entretanto, dentro do discurso proposto para essa exposição, talvez seja intencional esse modus-operandi: não seria preciso legenda para entender a consagração da figura do ex-prefeito feita naquela sala do Museu Hugo Simões Lagranha.

É possível identificar aproximações e distanciamentos entre o texto biográfico e a ex- posição de longa duração do Museu Municipal de Canoas. Ambos representam a vida do ex - prefeito a partir de momentos pontuais, sem se aprofundar ou fazer correlações sociais e políticas que influenciaram sua trajetória. As narrativas constroem sua trajetória política como predestinada, desconsiderando as rupturas e as dificuldades existentes na vida.

De acordo com Benito Schmidt (2012), o historiador interessado em realizar uma biografia deve fazer as seguintes perguntas: por que vale a pena biografar esse indivíduo? Quais dimensões do passado são possiveis de se conhecer pesquisando a trajetória de determinado personagem? Ao mesmo tempo em que é compreensivel a biografia de um prefeito da cidade, bem como haver uma coleção sua no museu, constatamos que o objetivo dessas práticas culturais, no caso, não é usar da narrativa biográfica para entender dimensões do passado da cidade. 0 foco dado é individual, numa lógica de consagração de um homem destacado.

Ambas as práticas só se estabelecem em decorrência da vontade de Hugo Simões Lagranha de ser lembrado e de ter sua existência prolongada e comunicada. Mas além do ex - prefeito, houve uma rede de interesse acerca da sua memória por parte do município, representada então pelo apoio que houve na promoção do livro biográfico e da readequação promovida na instituição museológica para abarcar sua figura na exposição de longa duração. Biografia e exposição sofrem, portanto, uma influência de Hugo Simões Lagranha, visto que sua biografia partiu de entrevistas e teve o texto final autorizado pelo prefeito. No caso da coleção, por terem sido objetos intimamente relacionados ao ex-prefeito e ter sido uma doação em decorrência da vontade dele.

A forma como foram montadas as narrativas - textual e expositiva - se assemelham também nos assuntos abordados: origem fa- 
miliar está presente na biografia e aparece a partir do brasão na exposição; o texto de João Palma da Silva está transcrito no livro e na exposição e as premiações recebidas pelo desempenho como gestor estão descritas em um capítulo da biografia e materializadas nos troféus expostos.

O distanciamento observado decorre das diferenças entre um texto escrito, que permite que o biógrafo introduza mais informações acerca do biografado, explicitando os rumos e os recortes de vida escolhidos, ao mesmo tempo em que na exposição, por não haver texto além da poesia de João Palma da Silva, as informações ficam subentendidas na narrativa expográfica proposta.

Por fim, essas duas práticas culturais de memória, biografia e coleção exposta, no caso de Hugo Simões Lagranha, desconsideram o contexto histórico e social e as múltiplas nuances da trajetória de vida. Convergem, desse modo, para a consagração da memória do ex-prefeito, pautada pela distinção e exemplaridade de sua figura. Enquanto a biografia o consagra com palavras, a exposição o consagra com objetos.

\section{Considerações finais}

As ideias aqui apresentadas resultam de investigação pontual sobre o Museu Municipal de Canoas e a biografia textual e material do ex-prefeito Hugo Simões Lagranha, mas que eventualmente podem contribuir para refletir sobre o lugar das coleções biográficas nos museus, especialmente para aqueles museus de pequeno porte, localizados em inúmeros municípios brasileiros. A biografia e a musealização das coleções pessoais continuam a configurar estratégias de perpetuação da memória individual. Entretanto, museus que consagram biografias em detrimento de sua missão são raros, a exceção de pequenos museus muni- cipais. Os que ainda persistem fogem à regra, são museus parados no tempo e espaço, formando uma espécie de Panteão contemporâneo. Os museus biográficos, muitas vezes caracterizados pela tipologia museu-casa, não se enquadram nessa discussão, mas podem também ser problematizados a partir de vários aspectos aqui abordados.

A partir das considerações expostas, há questões que latejam: Como, em pleno século $X X I$, se encontram museus dessa tipologia, detentores de coleções biográficas e narrativas individualizantes, focadas na glorificação de uma figura ilustre? E indo além, como no caso estudado, isso ocorre em instituições públicas, que dedicam sua missão a salvaguardar objetos que representam um coletivo de pessoas?

É necessário encarar essas práticas culturais com o olhar crítico do presente e entender o processo de seleção que envolve interesses de diversos sujeitos, grupos sociais e instituições. Tudo isso resulta na manutenção dessa concepção museológica e biográfica. Os museus são expressão de como os indivíduos lidam com a memória em cada localidade. São marcados pela memória que preservam, mas também pelas ausências que perpetuam. Nesse sentido, o Museu Municipal de Canoas, mais do que abordar a trajetória do ex-prefeito Lagranha, nos indica como a cidade e o poder público municipal lida com as memórias locais. Nesse sentido, é possivel constatar que o Museu se dedica à consagração de uma figura, em detrimento de muitas nuances que envolvem a história da cidade, que se constituiu desde 1733 com a participação de vários agentes sociais, enquanto o ex-prefeito fez parte dessa trajetória somente a partir de 1944.

Enquanto o Museu de Canoas se afastou das memórias da cidade para contemplar uma memória personalizada e consagradora de um indivíduo, outras instituições museológicas mudaram suas práticas no sentido oposto ao 
longo dos anos e atuam na contemporaneidade como espaços críticos de reflexão e mediação entre passado e presente. Desse modo, esses museus indicam outros caminhos possíveis para as coleções biográficas inseridas nos museus.

\section{Referências}

1a Região Museológica do Rio Grande do Sul. Arquivo Histórico e Museu Municipal Hugo Simões Lagranha. Disponivel em: https://1regiao.wordpress.com/ xi-mostra-conjunta-de-museus/imagem-003-2/. Acesso em: 10 nov. 2019.

ABREU, Regina. A fabricação do imortal: memória, história e estratégias de consagração no Brasil. Rio de Janeiro: Lapa/Rocco, 1996.

A MEMÓRIA do casamento é documentada no museu. Jornal de Canoas, Canoas, março de 1991. (Recorte de jornal).

ALMEIDA, Cícero Antônio Fonseca de. Objetos que se oferecem ao olhar: colecionadores e o "desejo de museu". In: BEZERRA, Rafael Zamorano; MAGALHÃES, Aline Montenegro. Coleções e colecionadores: a polissemia das práticas. Rio de Janeiro: Museu Histórico Nacional, 2012. 312 p.

ARQUIVO Histórico organiza exposição A viação férrea e a evolução da cidade. Folha de Canoas, Canoas, 06 de abril de 1994.

ARQUIVO Histórico promove exposição de Carnaval. Diário de Canoas, Canoas, 21 de fevereiro de 2003. (Recorte de jornal).

ARQUIVO HISTÓRICO E MUSEU DE CANOAS “DR. SEZEFREDO AZAMBUJA VIEIRA". Acervo de Peças. Canoas, 1989. Livro tombo, n. 1.

Acervo de Peças. Canoas, 2006. Livro tombo,

n. 2.

BAUMAN, Zygmunt. Modernidade líquida. Rio de Janeiro: Zahar, 2001.

BLANCO, Angela G. La exposición, um medio de comunicación. Madrid: Ediciones Akal, 2009.
BOURDIEU, Pierre. A ilusão biográfica. In: FERREIRA, Marieta de Moraes. AMADO, Janaína (org). Usos \& abusos da História Oral. Rio de Janeiro: Editora da Fundação Getúlio Vargas, 2006. p. 183-191.

BREFE, Ana Claudia Fonseca. Museu Paulista: Affonso de Taunay e a memória nacional. São Paulo: Editora UNESP/Museu Paulista, 2005.

BRUNO, Maria Cristina Oliveira. Museologia e museus: os inevitáveis caminhos entrelaçados. Cadernos de sociomuseologia, v. 25, no 25,2006 . p. 5-19. Disponivel em: https://core.ac.uk/download/ pdf/48579600.pdf. Acesso em: 15 nov. 2019.

CAMPACCI, Claudio. A heráldica e os sobrenomes. [s.n.], São Paulo, 2012, 148p.

CANOAS no I Fórum Estadual de Museus. Jornal de Canoas, Canoas, novembro de 1989, p. 5. (Recorte de jornal).

CANOAS no primeiro Encontro Latino-Americano de Museus. 0 Timoneiro, Canoas, setembro de 1990. (Recorte de jornal).

CARNEIRO, Cintia Braga. O Museu Paranaense e Romário Martins: a busca de uma identidade para o Paraná. Curitiba: SAMP, 2013.

CERTEAU, Michel de. A escrita da história. 3a ed. Rio de Janeiro: Forense-Universitária, 2011.

CHARTIER, Roger. Textos, impressão, leituras. In: HUNT, Lynn (org.). A nova História cultural. São Paulo: Martins Fontes, 1992. p. 211-238.

CHOAY, Françoise. A alegoria do patrimônio. Tradução de Luciano Vieira Machado. 3. ed. São Paulo: Estação Liberdade/UNESP, 2001.

CURY, Marília Xavier. Museu, filho de Orfeu, e musealização. ICOFOM LAM 99 VIII Encontro Regional Museologia, Filosofia e identidade na América Latina e no Caribe. Coro, Venezuela, 1999. Disponivel em: http://network.icom.museum/fileadmin/user_ upload/minisites/icofom/pdf/99.pdf. Acesso em: 15 nov. 2019.

DOHMMAN, Marcus. A experiência material: A cultura do objeto. Rio de Janeiro, Rio Books, 2013, 272p. 
EXPOSIÇÃO homenageia etnias. O Timoneiro, Canoas, 27 de agosto de 1998. (Recorte de jornal).

FUNDAÇÃO CULTURAL DE CANOAS. Hugo Simões Lagranha: período de 1968 a 1971. Canoas: Tecnicópias, 2009, 212p. (Histórias de nossos prefeitos; Série documento, v.8)

HARTOG, François. Regimes de historicidade: presentismo e experiências do tempo. Tradução de Andréa S. de Menezes, Bruna Breffart, Camila R. Moraes, Maria Cristina de A. Silva e Maria Helena Martins. Belo Horizonte: Autêntica, 2014

Tempo e história: "como escrever a história da França hoje?". História Social, n. 3, p. 127-154, 1996. Disponivel em: https://www.ifch.unicamp.br/ ojs/index.php/rhs/article/view/89. Acesso em: 15 nov. 2019.

HERNÁNDEZ, Francisca Hernández. Los museosy el patrimonio en una sociedad líquida In: MAGALHÃES, Fernando et all. (Orgs.). Museologia e patrimônio. Leiria: Instituto Politécnico de Leiria, 2019, p. 10-56.

LAGRANHA, Hugo Simões. 0 timoneiro. Canoas, 13-19 de julho de 2007. (Recorte de Jornal).

HUYSSEN, Andreas. Escapando da Amnésia: o museu como cultura de massa. Revista do Patrimônio Histórico e Artístico Nacional, n. 23, p. 34-55, 1994. Disponivel em: http://docvirt.com/Hotpage/ Hotpage.aspx?bib=RevIPHAN\&pagfis $=8370 \&$ url=http://docvirt.com/docreader.net. Acesso em: 15 nov. 2019.

JAEGER, Julia Maciel. A cidade no museu: representações da cidade de Canoas no Museu Hugo Simões Lagranha (Rio Grande do Sul, Brasil). 2017, 88 f. Trabalho de Conclusão de Curso - Faculdade de Biblioteconomia e Comunicação da Universidade Federal do Rio Grande do Sul, Porto Alegre, 2017. Disponível em: https:// lume.ufrgs.br/handle/10183/177718. Acesso em: 02 mai. 2020.

KOSELLECK, Reinhart. Futuro passado: contribuição à semântica dos tempos históricos. Trad. Wilma Patrícia Maas e Carlos Almeida Pereira. Rio de Janeiro: Contraponto/Ed. PUC Rio, 2006. Original em alemão.

LAMPERT, Adriana. Exposição lembra os 38 anos da
15 de Janeiro. Diário de Canoas, Canoas, 16 de janeiro de 1996. (Recorte de Jornal).

LE GOFF, Jacques. Memória. História e memória. Campinas, SP: Editora da Unicamp, 2003.

MAGALHÃES, Aline Montenegro. Cultuando a saudade: Sobre antiquariado e escrita da história no Museu Histórico Nacional. In: BITTENCOURT, José Neves; BENCHETRIT, Sarah Fassa; TOSTES, Vera Lúcia Bottrel. A história representada: o dilema dos museus. Rio de Janeiro: Museu Histórico Nacional, 2003, p. 97-112.

MALATIAN, Teresa Maria. A biografia e a História. Cadernos CEDEM. UNESP, v.1, no1, 2008, p. 16-31. Disponível em: http://www2.marilia.unesp.br/revistas/ index.php/cedem/issue/view/52. Acesso em: 17 nov. 2019.

MENESES, Ulpiano Toledo Bezerra de. Do teatro da memória ao laboratório da História: a exposição museológica e o conhecimento histórico. Anais do Museu Paulista. Nova Série, São Paulo, v. 2, jan./ dez., 1994.

Memória e cultura material: documentos pessoais no espaço público. Revista Estudos Históricos, Rio de Janeiro, v. 11, no 21, p. 89-104, jul. 1998. Disponivel em: <http://bibliotecadigital.fgv.br/ojs/ index.php/reh/article/view/2067>. Acesso em: 4 mai. 2018.

MUSEOLOGIA. Diário de Canoas, Canoas, 2 de abril de 1993. (Recorte de Jornal).

NORA, Pierre. Entre memória e história: a problemática dos lugares. Projeto História, no 10, p. 7-28, dez. 1993. Disponível em: https:// revistas. pucsp.br/ revph/article/view/12101. Acesso em: 17 nov. 2019.

OLIVEIRA, Magda de. Exposição comemora centenário do cinema. Diário de Canoas, Canoas, 20 de janeiro de 1998. (Recorte de Jornal).

OLIVEIRA, Márcia Ramos de. Reflexões sobre o gênero biográfico: literatura, ilusão e disputas de memória. In: GONÇALVES, Janice. História do tempo presente: oralidade-memória-mídia. Itajaí/SC: Editora Casa aberta, 2016, p.101-116.

OLIVEIRA, Miriam Kinczel de. Simplesmente Lagra- 
nha. Homem, marido, pai, político e administrador. Porto Alegre. Editora Evangraf, 2002, 88p.

OLIVEIRA, Priscila Musquim Alcântara de; OLIVEIRA, Alexandre Luís de. Sedução e desafios da biografia na história. Faces de Clio, vol. 1, no 1, Jan./Jun. 2015, p. 168-180. Disponivel em: http:// www.ufjf.br/facesdeclio/files/2014/09/1.10.Artigo-Priscila-e-Alexandre.pdf. Acesso em: 10 nov. 2019.

PEREIRA, Lígia Maria Leite. Algumas reflexões sobre histórias de vida, biografias e autobiografias. História oral, vol. 3, 2000, p. 117-27. Disponivel em: http://revista.historiaoral.org.br/index.php?journal=rho\& page=article\&op=view\& path\%5B\%5D=26. Acesso em: 10 nov. 2019.

POMIAN, Krzysztof. Colecção. Enciclopédia Einaudi. Porto: Imprensa Nacional /Casa da Moeda, 1984. p. 51-86.

POSSAMAI, Zita Rosane. As artimanhas do percurso museal: narrativas sobre objetos e peças de museu. Mouseion, v. 4, no 7, p. 64-72. Jan-Jun. 2010. Disponível em: https: / /revistas.unilasalle.edu.br/index.php/ Mouseion/article/view/164. Acesso em: 10 nov. 2019.

PRIORE, Mary Del. Biografia: quando o indivíduo encontra a história. Topoi, Rio Janeiro [on-line]. 2009, v. 10, no 19, p.7-16. Disponivel em: http:/ / www.scielo.br/ scielo.php? pid $=$ S2237=101-2009000200007X\&script- sci_abstract\&tlng=pt. Acesso em: 10 nov. 2019.

RODRIGUES, Ricardo Carvalho. Museu Paranaense: caminhos, contextos, ações museológicas e interações com a sociedade. Curitiba: SAMP, 2018.

SANTOS, Myrian S. A escrita do passado em museus históricos. Rio de Janeiro: Garamond: IPHAN, 2006, 142 p. (Coleção Museu, Memória e Cidadania; 1)

SCHMIDT, Benito Biso. História e Biografia. In: CARDOSO, Ciro Flamarion; VAINFAS, Ronaldo. Novos domínios da história. Rio de Janeiro, Editora Elsevier, 2012. p. 187-206.

SILVA, Ana Celina Figueira da. 0 museu e a consagração da memória de Júlio de Castilhos (19031925). 2011, 58 p. Trabalho de conclusão (graduação) - Universidade Federal do Rio Grande do Sul. Faculdade de Biblioteconomia e Comunicação. Curso de Museologia. Porto Alegre, 2011. Disponivel em: https://lume.ufrgs.br/handle/10183/40081. Acesso em: 12 fev. 2019.

SILVA, José. Exposição mostra a evolução da moeda no Brasil. Diário de Canoas, Canoas, 6 de setembro de 1995.

Recebido em: 15.01.2020

Revisado em: 10.05.2020

Aprovado em: 29.05.2020

Julia Maciel Jaeger é mestranda em Museologia e Patrimônio pela Universidade Federal do Rio Grande do Sul (UFRGS). Graduada em Museologia pela mesma Universidade.E-mail: juliamacieljaeger@gmail.com

Zita Rosane Possamai é doutora em História pela Universidade Federal do Rio Grande do Sul (UFRGS). Professora associada da UFRGS, exercendo suas atividades no curso de Museologia e no Programa de Pós-Graduação em Museologia e Patrimônio da Faculdade de Biblioteconomia e Comunicação e no Programa de Pós-Graduação em Educação, da Faculdade de Educação.E-mail: zitapossamai@gmail.com 